\title{
Simultaneous endoscopic ultrasound-guided treatment of intestinal and biliary obstruction due to massive lymphoma of the duodenal papilla
}

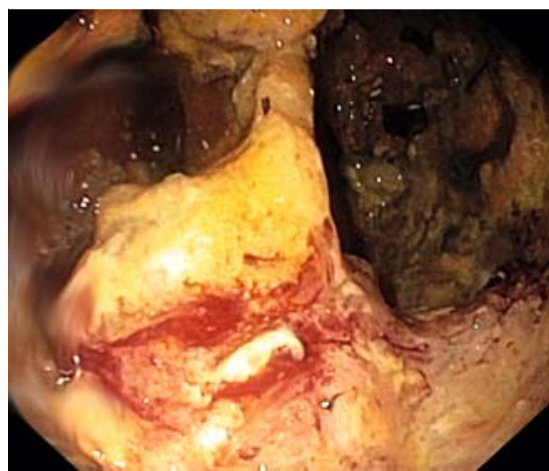

- Fig. 1 The cavity with massive neoplastic infiltration within the descending part of the duodenum visible in esophagogastroduodenoscopy.

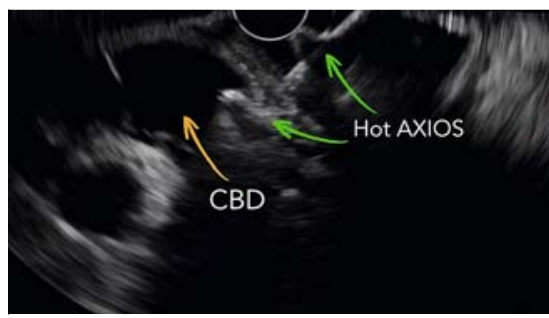

> Fig. 2 Choledochoduodenostomy created by Hot AXIOS stent $(6 \times 8 \mathrm{~mm})$. Orange arrow, common bile duct (CBD); green arrow, implanted Hot AXIOS stent.

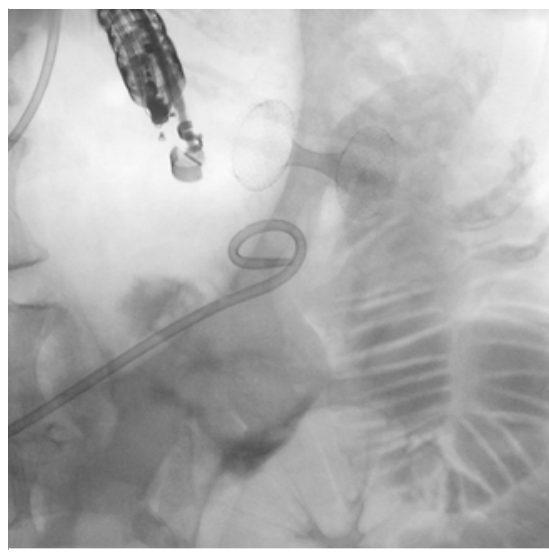

Fig. 3 Fluoroscopic image of gastrojejunostomy created by Hot AXIOS stent $(20 \times 10 \mathrm{~mm})$.

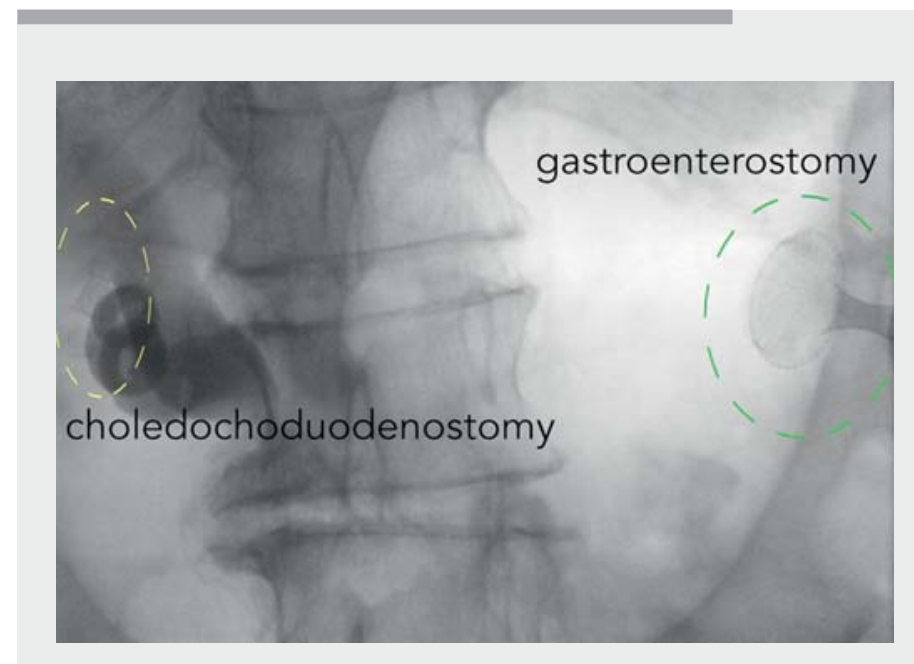

Video 1 Simultaneous endoscopic ultrasound-guided choledochoduodenostomy and gastrojejunostomy for treatment of intestinal and biliary obstruction due to massive lymphoma of the duodenal papilla.

Since endoscopic ultrasound (EUS)-guided anastomoses of the gastrointestinal (GI) tract were first performed for biliary [1] and Gl outlet obstructions [2], reported data have confirmed its safety and efficacy as an alternative modality for selected patients [3].

We report a case of a 78-year-old woman with a gastrointestinal and biliary tract obstruction due to B-cell lymphoma of the duodenal papilla who underwent simultaneous choledochoduodenostomy and gastrojejunostomy under EUS guidance ( $\bullet$ Video 1$)$.

The patient presented in the emergency department with symptoms of Gl tract obstruction and jaundice. Gastroscopy revealed a cavity with massive neoplastic infiltration within the descending part of the duodenum ( $\triangleright$ Fig.1). EUS showed metastatic lymph nodes and a double duct sign caused by a hypoechogenic tumor of the duodenal papilla infiltrating the duodenal wall and the head of the pancreas. EUS-guided fine needle aspira- tion confirmed the diagnosis of mucosaassociated lymphoid tissue (MALT) lymphoma.

The patient qualified for systemic treatment, however gastrointestinal and biliary patency had to be restored first, and therefore two anastomoses with lumenapposing metal stents (LAMSs) were created. The first procedure was a choledochoduodenostomy created with a $6 \times$ 8-mm Hot AXIOS stent (Boston Scientific, Marlborough, Massachusetts, USA) ( Fig. 2). For the subsequent gastrojejunostomy, a standard endoscope was used to pass a guidewire and a catheter through the infiltrated second part of the duodenum. Contrast solution was then injected under fluoroscopic guidance into the intestinal lumen. After endosonographic visualization of the optimal site, a $20 \times 10-\mathrm{mm}$ Hot AXIOS stent was implanted, followed by balloon dilatation of the stent lumen ( $\triangleright$ Fig.3). No complications were observed. After resolution of jaundice and normalization of 
laboratory parameters, the patient started systemic treatment without any symptoms of obstruction.

This case is of importance as it shows that creating anastomoses under EUS guidance allows minimally invasive treatment of GI tract and biliary tract obstruction during the same procedure. Furthermore, compared to surgery, this less invasive approach increases the patient's chance of receiving immediate systemic therapy with a higher likelihood of partial or complete remission.

Endoscopy_UCTN_Code_TTT_1AO_2AN

\section{Competing interests}

The authors declare that they have no conflict of interest.

The authors

\section{Artur Raiter ${ }^{1}$, Joanna Szełemej ${ }^{1}$, Katarzyna Kozłowska-Petriczko², Jan Petriczko³ Katarzyna M. Pawlak ${ }^{4}$ (ㄷ}

1 Department of Endoscopy, Specialist Hospital of Alfred Sokolowski, Wałbrzych, Poland
2 Department of Gastroenterology and Internal Medicine, SPWSZ Hospital, Szczecin, Poland

3 Department of Plastic, Endocrine and General Surgery, Pomeranian Medical University, Szczecin, Poland

4 Department of Gastroenterology, Hospital of the Ministry of Internal Affairs in Szczecin, Poland

\section{Corresponding author}

\section{Katarzyna M. Pawlak, MD, PhD}

Hospital of the Ministry of Internal Affairs, Jagiellońska 44, 70-382 Szczecin, Poland pawlakatarzyna@gmail.com

\section{References}

[1] Giovannini M, Moutardier V, Pesenti C et al. Endoscopic ultrasound-guided bilioduodenal anastomosis: a new technique for biliary drainage. Endoscopy 2001; 33: 898-900

[2] Coronel E, Chapman CG, Matthews J et al. Endoscopic ultrasound-guided gastroenterostomy for the treatment of gastroduodenal obstruction in severe chronic pancreatitis. Endoscopy 2018; 50: 285-287

[3] Simons-Linares CR, Chahal P. Advances in interventional endoscopic ultrasound (EUS): a technical review. J Clin Gastroenterol 2020; 54: 579-590

\section{Bibliography}

Endoscopy 2022; 54: E51-E52

DOI 10.1055/a-1375-0053

ISSN 0013-726X

published online 5.3.2021

(c) 2021. Thieme. All rights reserved.

Georg Thieme Verlag KG, Rüdigerstraße 14, 70469 Stuttgart, Germany

\section{ENDOSCOPY E-VIDEOS \\ https:|/eref.thieme.de/e-videos}

口回 Endoscopy E-Videos is an

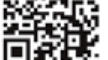
open access online section, reporting on interesting cases and new techniques in gastroenterological endoscopy. All papers include a high quality video and all contributions are freely accessible online. Processing charges apply (currently EUR 375), discounts and wavers acc. to HINARI are available.

This section has its own submission website at

https://mc.manuscriptcentral.com/e-videos 